\title{
A Comparative Study Of Ethical Work Climates Among Public And Private Sector Asian Accountants
}

\author{
Gerald Venezia, Hood College, USA \\ Chiulien Chuang Venezia, Frostburg State University, USA \\ Chung-wen Hung, Southern Taiwan University, Taiwan
}

\begin{abstract}
The purpose of this study is to determine whether a significant difference exists in the ethical behavior between public and private sector accountants. Current research has either focused on one sector or the other, leaving scant data for comparative studies. The public sector's focus on the intricacies of bureaucracy, emphasis on serving the public and sworn oaths to constitutions is bound and constrained by rules and law. The private sector, on the other, hand emphasizes entrepreneurship and risk-taking, encouraging creative approaches that challenge the parameters of the law, as well as answering to stake-holders. These differences toward decision-making influence their respective ethical choices. The 36-item revised version of Ethical Climate Questionnaire, developed by Bart Victor, John B. Cullen, (1987-1988), and James W. Bronson (1993), was the instrument used to evaluate the ethical perceptions of the accountants. Factor analysis results extracted seven dimensions and all of them originally identified from the based theory of Ethical Work Climate of Cullen, Victor, and Bronson (1993). They are Rules/Codes, Caring, Self-Interest, Social Responsibility, Efficiency, Instrumentalism, and Personal Morality. The results reflected the differences between the public and private sectors, emphasizing what is considered to be of optimum to each. The public sector showed a higher perception in rules/codes, caring, self-interests, social responsibility, and instrumentalism, while efficiency and personal morality were perceived higher in the private sector.
\end{abstract}

Keywords: Ethical Work Climate, ECQ, factor analysis, self-interest, social responsibility, efficiency, and personal morality

\section{INTRODUCTION}

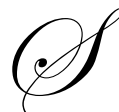

ervices in the public sector are usually provided free, with little or no ties between their costs and government income, mainly acquired through taxation. Accounts compare a government's agreed upon budget with actual payments and receipts. In contrast, accounts in the private sector are designed to demonstrate the level of profits achieved and retained. As Sonia Phippard (2000) pointed out in regard to ethical dilemmas between private and public sector, problems arise when behavior viewed as acceptable in one arena is not acceptable in another.

That does not imply that one sector is more ethical than another or that one country has a monopoly on ethical behavior, but there is a core of ethical standards common to most governments around the world (Phippard 2000). For accountants, core values are displayed in the Accounting Code of Ethics found within a governments CPA accountancy board. The Philippines bases its codes of ethics for accountants on the International Code of Ethics for Professional Accountants developed by the International Federation of Accountants (IFAC), which has a membership of 138 nations and 20 associate members. The role of the IFAC is to provide a global standard for accounting practices worldwide. Both the Philippines and Taiwan are listed as members of the IFAC. 


\section{LITERURE REVIEW}

\section{Base Theory}

Ethics or ethical values have extended and uncertain consequences, multiple alternatives, and personal implications. They are expected to be ideally possessed by an employee. The Ethical Work Climate, developed by John B. Cullen, Bart Victor (1988), and James W. Bronson (1993) state that organizations take into responsibility for any ethical or unethical actions that takes place among their employees and likewise can initiate and implement ethical work climate. "Ethical climates are conceptualized as general and pervasive characteristics of organizations, affecting a broad range of decisions" (Victor \& Cullen, 1988, p.101). The Ethical Climate Questionnaire is "simply an instrument to tap, through the perceptions of organizational participants, the ethical dimensions of organizational culture" (Victor \& Cullen, 1988, p.103). Therefore the participants becomes the "type of observer" who views different kinds of behavior, whether in decision-making or their compliance in the organization's practices and procedures; "but not evaluating the perceived organizational expectations" (Cullen, Victor, \& Bronson, 1993, p. 671).

The Ethical Climate covers two dimensions of theoretical typology of ethical climates (Victor \& Cullen, 1988); one dimension is ethical criterion, which is used for the organization's decision-making, and locus of analysis, the second dimension, refers to ethical decision-making.

The ethical criterion dimension is the dimension that covers three major classes of ethical theory (Victor \& Cullen, 1988) and these are egoism, benevolence, and principle. Labeled as three major classes of a group or organizational concept, they do not follow an individual's perception or behavior. Egoism is defined as "the maximization of self-interest" (VanSandt, 2001, p. 18). This means that a person believes in themselves, irrespective of opposed situations from society or opinions of other people to preserve its dignity as an individual. The second class is benevolence, where "people tend to be less cognizant of laws and rules and may also be amenable to arguments employing rules or principles" (Victor \& Cullen, 1988, p.105). This explains that an argument or discussion with a person who has lesser knowledge or ignorance of the law or rules might be ineffectual. Principle is the last class of ethical criterion dimension where "people who are principled tend to be less sensitive to particular effects on others" (Victor \& Cullen, 1988, p. 105). This kind of situation usually happens when a worker who is honest and loyal becomes the enemy of another when breaking office policies in the work place. The honest and loyal employee takes some action by reporting the other employee to the management without any second thoughts as long as they know that there is a violation of the policy.

Another part of the Ethical Work Climate is the locus of analysis dimension. This dimension represents the different sources of influences and motivation where a person might conceive its own perceptions on ethical or unethical issues. Victor \& Cullen (1988) stated that it "is a referent group identifying the source of moral reasoning used for applying ethical criteria to organizational decisions or the limits on what is considered the ethical analyses of organizational decisions" (p.105). Individual, local, and cosmopolitan are the categories that comprises the second dimension. This locus of analysis demonstrates that ethical climate is an organizational concept (Victor \& Cullen, 1988).

Locus of individual "is external to the focal organization in the sense that the prevailing normative climate supports a referent for ethical reasoning located within the individual" (Victor \& Cullen, 1988, p.106). This locus explains that perceiving a kind of work climate within an organization can depend on how an individual perceives its environment from their own point of view. While individual locus focuses on oneself, the local locus "specifies sources of ethical reasoning within the organization, such as the workgroup" (Victor \& Cullen, 1988, p. 106). Victor $\&$ Cullen (1988) also mentioned that for the local role incumbent, "the important reference group or sources of role definitions and expectations are contained within the social system" (p.106). This explains that within organizations, employees might perceive a positive or negative value depending on the type of group a person belongs. A group, which places a high value on morale, tends to influence an individual to perceive this kind of thinking; likewise the same with workgroups that place a low value on morale. 
A level, which specifies organizational sources of ethical reasoning external to the focal organization, such as professional associations or a body of law (Victor \& Cullen, 1988), is what is called cosmopolitan. Developed law-based environments use this locus to perceive norms or morale, which are acquired from other sources outside the organization.

Combining the two dimensions, ethical criterion and locus analysis, forms nine different criterions in order to describe the moral reasoning of an employee or individual.

The locus of the individual when combined with ethical criterions results in the following dimensions: egoism-individual (EI) results in self-interest, benevolence-individual (BI) resulting in friendship, and principleindividual (PI) results in personal morality. For local locus, combined with the ethical criterions creates: egoismlocal (EL) resulting in company profits, benevolence-local (BL) results in team interest, and principle-local (PL) explains the dimension of company rules and procedures. For the last three sets of dimensions, the analysis combination of ethical criterion and locus of analysis, the following are described: egoism-cosmopolitan (EC) forms the dimension, of efficiency while benevolence-cosmopolitan (BC) and principle-cosmopolitan (PC) form the dimensions of social responsibility and laws and professional codes respectively.

\section{Organizations/Institutions on Ethical Work Climate}

Studies of public and private organizations provide an overview on public organizations, revealing a greater moral awareness and responsibility. Public commitment perceives lesser ethical climates than private organization (Witmer \& Coursey, 1996). VanSandt's (2001) research explained the possible relationship of moral awareness and ethical climate, where mostly, moral awareness and ethical climate are always compared and/or combined in several research studies. From these studies, this research anticipates that organizations/institutions will reveal significant influence on ethical climate.

\section{METHODOLOGY}

This study aims to discover the ethical work climate (EWC) perceived by Public and Private Sector accountants. EWC dimensions will serve as the independent variables for this research study. The independent variables will determine whether the possible factors can show any significant effect on dependent variables, which are the Public and Private Sector accountants.

\section{Data Collection}

A total of 514 questionnaires were distributed, 265 from Philippines and 250 from Taiwan. The Philippine sample had an $83.40 \%$ response rate from 201 useful sets of questionnaires out of 265 sets distributed, where 46 sets were unusable and 18 sets unreturned. For the Taiwan sample, 163 sets of questionnaires were usable (out of 250 sets distributed), giving a $65.20 \%$ response rate. Forty sets were unusable, while the remaining 47 sets were not returned.

The variables for public and private sector accountants were gathered from 111 government accountants, or $30.5 \%$, and 253 private sector accountants, or $69.5 \%$.

\section{Factor Analysis}

Determining and performing the appropriate statistical analysis will indicate a more reliable and accurate result for the research study. Factor analysis and independent sample T-test are statistical methods used to extract and understand the relationships of the constructs.

Factor Analysis is a statistical method used to organize and simplify a number of constructs into a more comprehensive data in an economical way. This analysis helps in determining the possible ECQ dimensions possessed or perceived by the accountants. Although some suggested 0.6 or 0.4 as the cut-off points for factor loadings, this researcher applied 0.5 for this study. This was based on the rule of thumb suggested for checking constructs validity. The SAS program was used to analyze the data. Principal component factoring, principal axis factoring, and varimax rotation were the methods used in extracting the factors in the data analysis. 
Several procedures were done in performing factor analysis. Initially, there were eight factor loadings formed from the first procedure with a $60.620 \%$ of total variance explained. Kaiser-Meyer-Olkin measure is 0.888 which shows that the homogeneity of the constructs are adequate to continue running the factor analysis. The following sequence of procedures took place using Principal Component Factoring, Principal Axis Factoring, and Varimax Rotation in extracting the number of components to be used in this research study.

First, Kaiser's Measure of Sampling Adequacy (MSA) was performed to check whether there are values lower than 0.5. There were no constructs contained below 0.5 and MSA checking was satisfied. Second, construct validity took place using the Principal Component Factoring and Varimax Rotation. Constructs Q13, Q8, Q22, Q19, Q2, Q11, Q36, and Q27 contained factor loadings lower than 0.5 and were removed one by one after each rotation. Results of the final rotation with seven components were extracted. Principal Axis Factoring (PAF) was the third sequence performed after reversing the negative score of Q9. Final results showed that $63.04 \%$ of the total variance could be explained by the seven factors extracted. An RMSR equal to 0.025 shows a good factor structure, smaller than the 0.05 .

The second assessment is the reliability test. Cronbach Alpha Reliability test is satisfied where factors consisting of Cronbach alpha ranges from 0.35 (acceptable value) up to 0.860 indicate high reliability.

The results of the factor analysis are presented in Table1 below.

Table 1: Factor Analysis

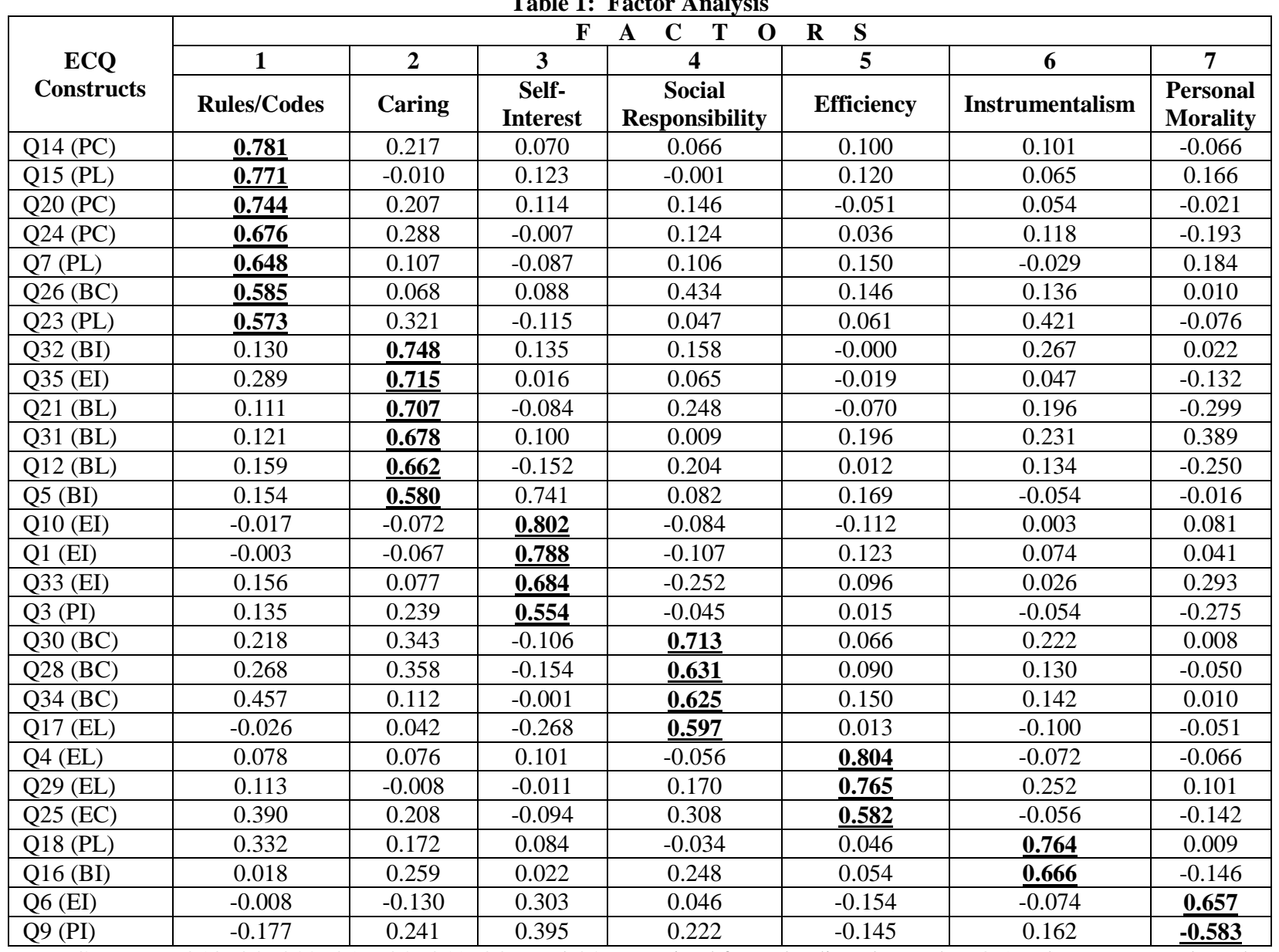

Note: Constructs Q13, Q8, Q22, Q19, Q2, Q11, Q36, and Q27 contained factor loadings lower than 0.5 and were removed one by one after each rotation 
Factor 1 (Rules/ Code) contains the dimensions of Principle-Cosmopolitan (PC), Principle-Local (PL) and Benevolence-Cosmopolitan (BC). Responses of participants loaded on the same factor that explains rules and regulations and laws and professional codes are treated in the same level, and serves as the first important ethical climate dimension in their organization.

Factor 2 (Caring) is the combination of Benevolence-Individual (BI), Benevolence-Local (BL), and Egoism-Individual (EI) dimensions of ECQ. Each constructs loaded in this factor describes that accountants perceived ethical climate of caring is more concerned in establishing and maintaining good relationship among coworkers.

Factor 3 (Self-Interest) is composed of constructs of Egoism-Individual (EI) and Principle-Individual (PI) dimensions. Factor loadings show that personal interest exists in the organization. Results indicate that people in the organization tend to perform their task with their own way to fulfill personal satisfaction.

Factor 4 (Social Responsibility) contains Benevolence-Cosmopolitan (BC) and Egoism-Local (EL) dimensions of the ethical work climate. The result of the factor loadings explains that individuals perform their tasks with their level best for the organization while taking precautions for social awareness or responsibility.

Factor 5 (Efficiency) is the combination of Egoism-Local (EL) and Egoism-Cosmopolitan (EC) dimensions. Company profit and efficiency comprise the factor loadings. Individuals see their organization mostly concerned in attaining greater profit while efficiency is being observed by each employees.

Factor 6 (Instrumentalism) is the combination of Principle-Local (PL) and Benevolence-Individual (BI). This factor is described differently and the label is not among the nine dimensions of ECQ. Each construct contains different purposes that lead to assumption that each constructs acts as a "means" or an "aid" in providing solutions for a certain circumstance to occur in the organization.

Factor 7 (Personality Morality) is formed by the constructs of Principle-Individual (PI). Factor loadings explain that most of the individuals are morally responsible for their actions distinguishing "right from wrong" and/or to be "ethical or unethical".

\section{RESEARCH HYPOTHESES}

Arnaud and Schminke (2006) stated that ethical work climate is the shared perceptions regarding prevalent ethics-related values, norms, attitudes, and behaviors among members of a social system. Their view parallels Victor and Cullen's (1988) definition that ethical work climate reflects employees' collective perceptions of ethical events, ethical practices, and procedures. The ethical climate covers two-dimensional areas which are the locus of analysis (the individual, local, and cosmopolitan) that deals with the perceived values from different sources of influence and motivation, while ethical criterion (principle, benevolence, and egoism), deals with the perceived values from a group or organization. From there, ethical climate produces nine ethical climate dimensions such as self-interest, friendship, personal morality, company profit, team interest, company rules and procedures, efficiency, social responsibility, and the laws and professional codes that represent the values that individuals might conceive within their organization. Using these theoretical aspects of ethical climate, this research study will focus on understanding the ethical work climate values that Public and Private Sector accountants perceive from their organization or institution.

After acknowledging the factors that identify the ethical values, we will determine if there is a significant difference between Public and Private Sector accountants on the perceived ethical work climate value(s) from their organization or institution. 
Table 2: Independent Sample T-test on ECQ Dimensions

\begin{tabular}{|c|c|c|c|}
\hline \multirow{2}{*}{ ECQ DIMENSIONS } & M E A N S C O R S & \multirow{2}{*}{ SIGNIFICANCE } \\
\cline { 2 - 4 } Overall & Government & Private & 0.004 \\
\hline Rules/Codes & 3.5751 & 3.4354 & 0.0077 \\
\hline Caring & 4.0721 & 3.8763 & 0.0013 \\
\hline Self-Interest & 3.4324 & 3.1891 & 0.0072 \\
\hline Social Responsibility & 3.2432 & 3.0128 & 0.0470 \\
\hline Efficiency & 3.5901 & 3.4289 & $<0.0001$ \\
\hline Instrumentalism & 3.7928 & 4.2477 & $<0.0001$ \\
\hline Personal Morality & 3.4009 & 3.0474 & 0.0013 \\
\hline
\end{tabular}

$\mathbf{H}_{1}$ : $\quad$ Government and Private sectors have no significant influence as a moderating variable on perceived Rules/Codes dimension from their organization or institution.

Table 2 showed that government and private sectors have significant influence as a moderating variable on the ethical work dimension of Rules/Codes with p-value of 0.0077, less than the set significant level of 0.05. Mean scores between government and private is 4.0721 and 3.8763, respectively. Government sectors value or follow Rules/Codes as "mostly true" and private as "somewhat true" in their organization or institution.

$\mathbf{H}_{2}$ : $\quad$ Government and Private sectors have no significant influence as a moderating variable on perceived Caring dimension from their organization or institution.

Table 2 showed that government and private sectors have significant influence as a moderating variable on the ethical work dimension of Caring with p-value of 0.0013, less than the set significant level of 0.05 . Mean scores between government and private is 3.4324 and 3.1891, respectively. They value or follow Caring as "somewhat true" in their organization or institution.

$\mathbf{H}_{3}$ : $\quad$ Government and Private sectors have no significant influence as a moderating variable on perceived SelfInterest dimension from their organization or institution.

Table 2 showed that government and private sectors have significant influence as moderating variable on the ethical work dimension of Self-Interest with p-value of 0.0072 , less than the set significant level of 0.05 . Mean scores between government and private is 3.2432 and 3.0128, respectively. Government sectors value or follow SelfInterest as "somewhat true" and private as "somewhat false" in their organization or institution.

$\mathbf{H}_{4}$ : Government and Private sectors have no significant influence as a moderating variable on perceived Social Responsibility dimension from their organization or institution.

Table 2 showed that government and private sectors have significant influence as a moderating variable on the ethical work dimension of Social Responsibility with p-value of 0.0470 , less than the set significant level of 0.05 . Mean scores between government and private is 3.5901 and 3.4289, respectively. They value or follow Social Responsibility as "somewhat true" in their organization or institution.

H5: Government and Private sectors have no significant influence as moderating variable on perceived Efficiency dimension from their organization or institution.

Table 2 showed that government and private sectors have significant influence as moderating variable on the ethical work dimension of Efficiency with p-value of $<0.0001$, less than the set significant level of 0.05. Mean scores between government and private is 3.7928 and 4.2477, respectively. Government sectors value or follow Efficiency as "somewhat true" and private as "mostly true" in their organization or institution.

H6: Government and Private sectors have no significant influence as moderating variable on perceived Instrumentalism dimension from their organization or institution. 
Table 2 showed that government and private sectors have significant influence as moderating variable on the ethical work dimension of Instrumental with p-value of $<0.0001$, less than the set significant level of 0.05 . Mean scores between government and private is 3.4009 and 3.0474, respectively. They value or follow Instrumentalism as "somewhat true" in their organization or institution.

$\mathbf{H}_{7}$ : Government and Private sectors have no significant influence as a moderating variable on perceived Personal Morality dimension from their organization or institution.

Table 2 showed that government and private sectors have significant influence as moderating variable on the ethical work dimension of Personal Morality with p-value of 0.0013, less than the set significant level of 0.05 . Mean scores between government and private are 2.5270 and 2.8024, respectively. These sectors value or follow Personal Morality as "somewhat false" in their organization or institution.

\section{RESULTS AND DISCUSSION}

The hypothesis showed significant influence as a moderating variable among the ethical climates. The results of mean scores from Table 2 reflected the differences between the public and private sectors. Public sectors have standard rules and procedures. These rules are related to constitutional law and civil ethics rules, as well as professional conduct for accountants, which are set by government agencies. Accountants from private organizations may follow the accountant's professional code of conduct but risk taking and entrepreneurship are generally encouraged. There is also greater latitude toward making one's own decision. In line with the rules and procedures in private organizations, accountants perceived greater Efficiency and Personal Morality. The mean scores of the two dimensions suggest that accountants from private organizations are more diligent in following and supplying the necessary needs of others as well as fulfilling the company's interest, more than the accountants from government.

\section{Limitations of the Study}

The research study is limited within the metropolitan areas and main cities of Philippines and Taiwan. Makati City, Manila, Mandaluyong City, and Quezon City are the areas where Philippine respondents were measured. Taipei City and Tainan are the only areas that comprise the Taiwan sample. This is due to the researcher's accessibility and capacity to conduct a wider scope of research. The results may not represent the perception of the whole population of accountants in the Philippines and Taiwan.

\section{AUTHOR INFORMATION}

Gerald Venezia, DPA, is an adjunct assistant professor with the department of Global Studies at Hood College. Dr. Gerald Venezia spent three years teaching in Asia researching issues pertaining to East Asia and globalization before returning to the United States. His areas of research are in comparative government and politics and the social, economic and political affects of globalization.

Chiulien C. Venezia, DBA, CPA, has been teaching Accounting since 1992. She is an assistant professor of Accounting at Frostburg State University, Maryland. Her Research Interests include Cross-cultural ethics, Earnings management, and Financial performance. She has published papers in the International Business \& Economics Research Journal, the Journal of American Academy of Business, Cambridge, and Journal of Nan Tai College.

Chung-Wen Hung, Ph D. has been teaching Accounting Information System since 2005. He is an assistant professor of Accounting Information at Southern Taiwan University. His Research Interests include Financial Management, Corporate Finance and Enterprise Resource Planning. He has published papers in the Journal of Financial Studies, International Journal of Global Logistics \& Supply Chain Management and Journal of Southern Taiwan University. 


\section{REFERENCES}

1. Accounting Research and Development Foundation in Taiwan (ARDF) (2005). [Web document]. Available: http://www.ardf.org.tw/english/. [2007, 11 April].

2. $\quad$ Andres, T.D. (1989). Positive Filipino Value. New Day Publishers.

3. Arnaud, A.U., \& Schminke, M. (2006). Beyond the organizational bases of ethical work climates: a new theory and measure. [Web document]. Available:

http://www.business.uiuc.edu/aguilera/Papers/schminke\%202006.doc. [2006, 31 August].

4. Certified Public Accountant Association, R.O.C (ROCCPA) (2002). Code of Ethics for Professional Accountants. [Web document]. Available: http://www.roccpa.org.tw/Download.php. [2007, 15 June].

5. $\quad$ Church, T., Katigbak, M., del Prado, A., Valdez-Medina, J.L., Miramontes, L., \& Ortiz (2006). A crosscultural study of trait self-enhancement, explanatory variables, and adjustment. Journal of Research in Personality, 40, 1169-1201.

6. Church, T.A.; \& Katigbank, M.S. (2000). Trait Psychology in the Philippines. The American Behavioral Scientist, 44, 1, 73-94.

7. $\quad$ Church, T.A. (1989). Filipino Personality: A Review of Research and Writings. Manila, DLSU Press 1988.

8. Church, T.A. (1987). Personality Research in a Non-Western Culture: The Philippines. Psychological Bulletin, 102, 2, 272-292.

9. Cohen, D.V. (1995). Moral climate in business firms: A framework for empirical research. Academy of Management Journal, 1995, 386-390.

10. Cullen, J.B., Victor, B., \& Bronson, J.W. (1993). The ethical climate questionnaire: an assessment of its development and validity. Psychological Reports, 73, 667-674.

11. Datu-Evangelista, R. (1997). Ethics: the soul of a globalized practice of accountancy. Accountants' Journal, 50 (3\&4), 30-38.

12. ESLIsland.com (2003). History of Taiwan. [Web document].Available: http://www.eslisland.com/intro/History.html. [2007, 11 April].

13. ESLIsland.com (2003). Taiwan Culture. [Web document]. Available: http://www.eslisland.com/intro/Culture.html. [2007, 11 April].

14. Huang, Y. (2000). The personal influence model and gao guanxi in taiwan chinese public relations. Public Relations Review, 1-8.

15. Lau, D.C.(tanslated) (1979). Confucisus The Analects. England UK: Penguin Book.

16. Lewis, T. (2006). Comment inside the moral maze. Public Finance; Accounting Tax \& Periodicals, Jun30Jul 6, 2006, 17.

17. Parboteeah, K.P., Cullen, J.B., Victor, B., \& Sakano, T. (2005). National culture and ethical climates: a comparison of U.S. and Japanese accounting firms. Management International Review, 45 (4), 459-481.

18. Philippine Institute of Accountants (PIA) (1957). The First Far East Conference of Accountants 1957 (28th, 29th, \& 30th of November and 1st December 1957) Senate Hall Congress Bldg., Manila. National Printing, Co., Inc., Manila Philippines.

19. Philippine Regulation Commission (PRC) (2004). Board of Accountancy - Board Law. [Web document]. Available: http://www.prc.gov.ph/portal.asp?pid=34. [2007, 16 June]

20. Phippard, S. (2000). Hong Kong Speech. Available: http://www.csb.gov.hk/hkgcsb/rcim/pdf/english/conference materials/phippard.pdf. [March 29, 2009]

21. Ponemon, L.A. (1990). Ethical judgments in accounting: a cognitive-developmental perspective. Critical Perspective on Accounting, 1, 191-215.

22. SPSS, Inc. (1999). SPSS Base 10.0 Application Guide. Chicago, Illinois, USA: SPSS, Inc.

23. VanSandt, C.V. (2001). An examination of the relationship between ethical work climate and moral awareness. Unpublished doctoral dissertation, Virginia Polytechnic Institute and State University, USA.

24. Vardi, Y. (2001). The effects of organizational and ethical climates on misconduct of work. Journal of Business Ethics, 29 (4), 325-337.

25. Victor, C. \& Cullen, J.B. (1988). The organizational bases of ethical work climates. Administrative Science Quarterly, 33 (1), 101-125.

26. Victor, C. \& Cullen, J.B. (1987). A Theroy and Measure of Ethical Climate in Organizations. Research in Social Performance \& Policy, 9 ,1987, 51-72. 
27. Wittmer, D., \& Coursey, D. (1996). Ethical work climates: comparing top managers in public and private organizations. Journal of Public Administration Research and Theory, 6 (4), 559-572.

28. Woodbine, G.F. (2006). Ethical climate types and job satisfaction: study of Chinese financial institutions. International Review of Business Research Papers, 2 (1), 86-99.

29. Wu, M., Taylor, M., \& Chen, M. (2001). Exploring societal and cultural influences in Taiwanese public relations. Public Relations Review, 27, 317-336. 
NOTES 